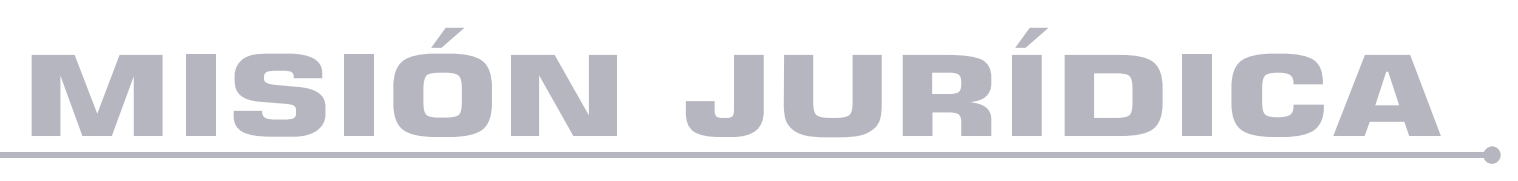

El arbitraje social como manifestación de la Responsabilidad Social Empresarial de la Cámara de Comercio de Bogotá: canal de acceso a la administración de justicia en Colombia

Social arbitration as a demonstration of corporate social responsibility of Bogotá Chamber of Commerce: Resource of access to justice in Colombia

Autor: Rosa del Mar Beltrán Cucarián

DOI: https://doi.org/10.25058/1794600X.1956

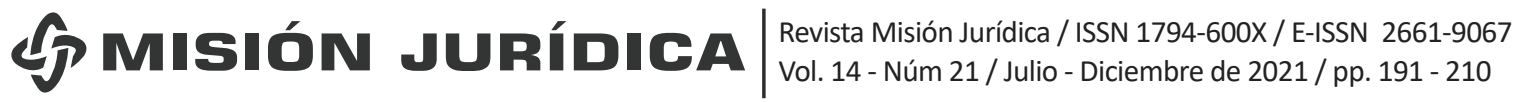




\title{
El arbitraje social como manifestación de la Responsabilidad Social Empresarial de la Cámara de Comercio de Bogotá: canal de acceso a la administración de justicia en Colombia*
}

\author{
Social arbitration as a demonstration of corporate social \\ responsibility of Bogotá Chamber of Commerce: Resource of \\ access to justice in Colombia
}

Arbitragem social como manifestação da Responsabilidade Social Corporativa da Câmara de Comércio de Bogotá: canal de acesso à administração da justiça na Colômbia

Rosa del Mar Beltrán Cucarián ${ }^{a}$ rosadelmarb@gmail.com

Fecha de recepción: 10 de octubre de 2020 Fecha de revisión: 20 de noviembre de 2020 Fecha de aceptación: 26 de febrero de 2021

DOI: https://doi.org/10.25058/1794600X.1956

Para citar este artículo:

Beltrán, R. (2021). El arbitraje social como manifestación de la Responsabilidad Social Empresarial de la Cámara de Comercio de Bogotá: canal de acceso a la administración de justicia en Colombia. Revista Misión Jurídica, 14, (21), 191-210.

\section{RESUMEN}

La crisis de la justicia en Colombia ha permitido que el Estado, como garante del goce efectivo de los derechos, incorpore nuevos recursos para solucionar los conflictos. Atendiendo a esta realidad, se plantea como objetivo de este artículo, hacer un análisis acerca del acceso a la administración de justicia por parte de las micro, pequeñas y medianas empresas a través del arbitraje social, centrando la atención en la Cámara de Comercio de Bogotá.

La metodología empleada se escogió a partir de la profundización que se hizo en la doctrina local referente a la justicia, el arbitraje y la responsabilidad social empresarial como una herramienta encaminada a contribuir para la paz. Asimismo, para ello se consideró la revisión documental de los laudos proferidos por la Cámara de Comercio de Bogotá entre 2009 y 2014, en las Jornadas Gratuitas de Arbitraje Mipymes que se adelantaron, con el fin de aportar a la solución efectiva de los conflictos de carácter comercial. Del análisis conjunto de la información sustraída en las fuentes consultadas, se identificó que el arbitraje social es un mecanismo adecuado que posibilita la solución de los conflictos para las Mipymes y lo relacionado con las cuantías que atiende.

\footnotetext{
* Artículo de revisión. Maestría en derecho con énfasis en derecho privado, Universidad Colegio Mayor de Nuestra Señora del Rosario.

a. Abogada egresada de la Universidad Libre de Colombia, Especialista en Derecho Procesal de la misma universidad, estudiante de Maestría del Colegio Mayor de Nuestra Señora del Rosario (Bogotá, Colombia). Conciliadora en derecho.
} 


\section{PALABRAS CLAVE}

Acceso a la justicia; arbitraje social; Cámara de Comercio; laudo arbitral; Responsabilidad Social Empresarial.

\section{ABSTRACT}

The crisis of justice in Colombia has allowed the State, as a guarantor of the effective enjoyment of rights, to implement new resources towards conflict resolution. The objective of this article is to analyze the access to the administration of justice through social arbitration that micro, small and medium-sized companies have, focusing on the Chamber of Commerce of Bogotá.

The methodology used is based on the study of the local doctrine regarding justice, arbitration and corporate social responsibility as a tool towards peacebuilding. Additionionally, for that purpose a documentary review of the arbitration awards issued by the Chamber of Commerce of Bogotá between 2009 and 2014 during the free arbitration sessions that were performed in order to contribute to the effective conflict resolutions of a commercial nature. From the joint analysis of the information obtained from the sources consulted this article concludes that social arbitration is the most appropriate mechanism to deal with conflict resolution of MSMEs and that is related to the amounts it covers.

\section{KEYWORDS}

Access to justice; social arbitration; arbitration award; Chamber of Commerce; Corporate Social Responsibility.

\section{RESUMO}

A crise da justiça na Colômbia permitiu ao Estado, como garante do gozo efetivo dos direitos, incorporar novos recursos para a solução de conflitos. Diante dessa realidade, o objetivo deste artigo é fazer uma análise sobre o acesso à administração da justiça pelas micro, pequenas e médias empresas por meio da arbitragem social, com foco na Câmara de Comércio de Bogotá.

A metodologia utilizada foi escolhida a partir do aprofundamento que se fez na doutrina local sobre justiça, arbitragem e responsabilidade social empresarial como ferramenta que visa contribuir para a paz. Da mesma forma, para o efeito, considerou-se a revisão documental dos laudos emitidos pela Câmara de Comércio de Bogotá entre 2009 e 2014, nas Conferência de Arbitragem Gratuita MPMEs realizadas a fim de contribuir para a solução eficaz de conflitos de natureza. A partir da análise conjunta das informações furtadas das fontes consultadas, identificouse que a arbitragem social é um mecanismo adequado que possibilita a resolução de conflitos para as MPMEs e o que está relacionado com os valores por ele atendidos.

\section{PALAVRAS CHAVE}

Acesso à justiça; arbitragem social; Câmara de comércio; laudo arbitral; Responsabilidade social Empresarial.

\section{INTRODUCCIÓN}

Colombia, en cuanto Estado social de derecho, tiene el deber de cumplir, entre otras obligaciones, la de proteger los derechos fundamentales de todos sus habitantes. Uno de estos es el acceso a la administración de justicia, derecho fundamental al que le han otorgado varios fallos del más alto Tribunal Constitucional colombiano pues, debido a que este poseía las características propias de los derechos fundamentales, lo homologó al vocablo tutela judicial efectiva, como se indicó en la Sentencia C-037 de 1996. De igual forma, Castilla (2012) mencionó que "el derecho a la tutela judicial efectiva comprende, primordialmente, el derecho de acceso a la jurisdicción, es decir, el derecho a provocar la actividad jurisdiccional que desemboque en una decisión judicial" (p. 8).

El derecho fundamental de acceso a la administración de justicia implica reconocer a todas las personas residentes en Colombia, la posibilidad de acudir en condiciones de igualdad ante los jueces para solicitar la protección o el restablecimiento de sus derechos, lo cual debe estar sujeto a los procedimientos previamente establecidos, que deben observar las garantías sustanciales señaladas en la ley (Sentencia T-799, 2011). Si bien, el acceso a la justicia por parte de las personas naturales y jurídicas ha sido una preocupación constante para los diferentes gobiernos colombianos, desde un principio el Estado, como garante del goce efectivo de los derechos, ha tenido que afrontar situaciones de crisis de la justicia y emprender acciones que le 
permitan a sus ciudadanos elegir la forma como desean solucionar sus conflictos (Ilera, 2017).

De ese modo, surgieron los Mecanismos Alternativos de Solución de Controversias (MASC, en los sucesivo), en medio de la necesidad por atender el sinnúmero de circunstancias que afectan la convivencia y que la justicia estatal no alcanza a satisfacer. Estos métodos se elevaron a rango constitucional con la expedición de la carta política de 1991, en la cual se determinó que "los MASC son formas de administración de justicia muy diferentes a los procedimientos judiciales, pero que se complementan con la finalidad de dirimir conflictos" (Herrán, 2013, p. 117). En correspondencia con lo anterior, Silva y Martínez (2019) afirmaron que:

es importante reconsiderar que el acceso a la justicia alternativa ha estado previsto como un derecho humano, por lo que el conocimiento y difusión de estos temas en diversos aspectos, como el académico, permite fortalecer la divulgación de la justicia alternativa como derecho humano a todo ciudadano universal (p. 265).

Así las cosas, dichos MASC hacen parte de la justicia procesal, la cual hace referencia a la administración y establecimiento de un sistema justo dentro de las instituciones (Ospino, 2010), permitiendo la posibilidad de toda persona para dar solución a sus conflictos a través de la intervención de un tercero neutral, que puede ser el Estado o un particular. Este tipo de justicia soporta las distintas herramientas que el Estado colombiano dispuso para el acceso a la administración de justicia y por eso será unos de los derroteros en los que se encuentra fundamentado el presente escrito.

Ahora bien, dentro de la gama de posibilidades que componen los MASC se encuentran el arreglo directo, la mediación, la conciliación, la amigable composición y el arbitraje, este último será de especial atención en este artículo, concentrándose en el arbitraje social que la Ley 1563 de 2012 designó, debido a la especialidad en materia comercial y contractual con la que atiende estas disputas que surgen entre las mismas micro, pequeñas y medianas empresas (en lo sucesivo, mipymes) o entre ellas y las personas naturales que también ejercen actividades mercantiles o que tienen alguna relación comercial con estas (Rey, 2013).

Con la expedición del Estatuto de Arbitraje se estableció que las cámaras de comercio, además de promover el arbitraje en el país, al igual que los otros mecanismos, deben realizar jornadas de arbitraje social para resolver controversias cuya cuantía sea hasta de 40 Salarios Mínimos Legales Mensuales Vigentes - SMLMV (Ley 1563, 2012, art. 117). Lo anterior como parte de su Responsabilidad Social Empresarial -RSE-, y en atención al deber constitucional de solidaridad que les corresponde de actuar como facilitadoras de paz en los territorios. En esas jornadas se involucraron a los empresarios en la creación de una cultura pacífica, pues dichas "acciones implican una permanente construcción y en el cual los empresarios y gerentes tienen un importante rol a desempeñar" (Ravina-Ripoll, Gálvez-Albarracín y Otálvaro-Marín, 2020, p. 309).

De lo indicado, surge la pregunta ¿Cómo la Responsabilidad Social Empresarial de la Cámara de Comercio de Bogotá incide en el arbitraje social como un canal de acceso a la administración de justicia en Colombia?

Para responder a esta cuestión se necesita: en un primer momento, identificar los elementos del acceso a la administración de justicia, centrando la atención en los MASC; posteriormente, analizar los aportes del arbitraje en Colombia, especialmente el arbitraje social. Como tercer aspecto, del presente escrito, es indispensable identificar el rol de la RSE de las cámaras de comercio; y, por último, describir los laudos arbitrales proferidos en las Jornadas Gratuitas de Arbitraje Mipymes.

\section{METODOLOGÍA}

El presente artículo pretende identificar la incidencia de la RSE de la Cámara de Comercio de Bogotá -CCB- en el arbitraje social con el fin de determinar diferentes alternativas que las mipymes, y quienes se relacionen con ellas comercialmente, pueden utilizar sin acudir a los estrados judiciales, para solucionar sus conflictos. Para este propósito se empleó la metodología cualitativa, siguiendo el método de revisión documental que permitió indagar en la jurisprudencia y doctrina colombianas, facilitando la contextualización sobre los orígenes del arbitraje, su alcance, fundamento, competencia, 
así como las críticas y elogios que se han hecho hacia esta figura. Por otro lado, se realizó una exploración de los laudos arbitraᄀles proferidos entre los años 2009 a 2014, en las bases de datos de la Biblioteca Digital del Centro de Información Empresarial de la CCB, usando como recurso de búsqueda la combinación de las palabras "Laudos arbitrales mipymes", la fecha de expedición del laudo y el nombre del árbitro que lo haya decidido.

Una vez realizada la investigación se hallaron 10 laudos, lo que permitió indagar la tipología de los asuntos resueltos, la calidad de las partes inmersas en el conflicto y la celeridad en el que fueron pronunciados.

\section{Acceso a la administración de justicia}

El acceso a la administración de justicia es un derecho fundamental que está consagrado en el artículo 229 de la Constitución Política de Colombia. En virtud de lo anterior, "no puede existir duda alguna de que se trata de un derecho fundamental, no consagrado explícitamente en la carta política, pero en desarrollo de los mismos postulados el Alto Tribunal Constitucional le ha atribuido características propias de un derecho fundamental" (Cortés, 2015, p. 101).

Por ello, es considerable la jurisprudencia de la Corte Constitucional colombiana en esta materia, puesto que en algunas sentencias se ha homologado al vocablo tutela judicial efectiva, por la cual se entiende el efectivo amparo de los derechos reclamados ante los órganos del Estado que administran justicia. Esta posición se evidenció en la Sentencia C-279 de 2013 (Corte Constitucional, M.P. Jorge Ignacio Pretelt Chaljub, 2013); no obstante, en la Sentencia C-426 de 2002 (Corte Constitucional, M.P. Rodrigo Escobar Gil, 2002) se estableció que el derecho de acceso a la justicia es similar, pero no es igual al derecho a la tutela judicial efectiva, dado que el primero es el derecho general del que toda persona residente en Colombia goza, mientras que el segundo es el efectivo cumplimiento del derecho conculcado. Dentro de este argumento, González (2018) señaló:

El derecho de acción corresponde a una visión formalista y científica que endilga al ciudadano la posibilidad de acceder a la jurisdicción; el derecho a la tutela judicial efectiva por el contrario es la rematerialización, la constitucionalización del derecho de acción, entendido como derecho fundamental; el acceso a la justicia, por el contrario, desde un enfoque propio de la sociología del derecho desentraña las barreras y ensalza los mecanismos para ingresar a la jurisdicción en busca de tutela, de justicia (p. 40).

Si bien, para algunos autores equiparar el derecho de acceso a la justicia al de la tutela judicial efectiva es un error, para otros este derecho fundamental reúne varios aspectos en los que coinciden. Al respecto, Araújo (2011) señaló que "el derecho fundamental de acceso a la justicia se relaciona con el servicio de administración de justicia y con la función de impartir justicia" (p. 250 ), pues es notable que la expresión justicia remite necesariamente a las diversas formas de su materialización a través de las instituciones consagradas en la Constitución Política de Colombia como, por ejemplo: el Estado social de derecho, los fines esenciales del Estado, el debido proceso y la administración de justicia. De modo que "la importancia del acceso a la justicia en el ámbito de la Carta Constitucional que impone al Estado el deber de garantizar la prestación del servicio de justicia de manera integral" (Illera, 2017, p. 145).

Por otra parte, el derecho a la administración de justicia está enmarcado en el artículo 228 de la Constitución Política como función pública, lo cual significa que:

la administración de justicia es un servicio público, cuyo objeto es proveer en forma permanente y continua justicia a los conflictos jurídicos que son de su conocimiento para solucionarlos pacíficamente, procurando la ejecución de lo juzgado por tribunales independientes e imparciales, dentro de un marco de garantías procesales previamente establecidas por el ordenamiento jurídico (Araújo, 2011, p. 249).

A partir de la promulgación de la Ley 270 de 1996, también llamada Ley Estatutaria de la Administración de Justicia, se establecieron los principios que la regularían, y la finalidad del legislador estuvo orientada a mantener la paz social, para que la sociedad colombiana viviera en sana convivencia. Sin duda, "la importancia de los principios de la administración de justicia radica en que son la base para la construcción de 
la política pública de la administración de justicia" (Herrán, 2013, p. 121). De igual forma, se plantea su importancia en los siguientes términos:

El acceso a la justicia, dentro del modelo de Estado de corte social, adquiere relevancia frente a la materialidad, cuando se trata el tema en los artículos 229 y 228 de la carta política, como un desarrollo de corte institucional, con necesidad de aplicación, el cual se hace tangible en el derecho de acción ciudadana de acceso al sistema judicial, en busca de una verdad, con un carácter procesal, a fin de lograr una justicia pronta y oportuna (Cortés, 2015, p. 84).

Frente a este panorama, la opinión que tienen los habitantes en Colombia acerca del acceso a la administración de justicia es variable, y su percepción depende del componente que se aborde en relación con la administración de justicia. En aras de explicar este hallazgo López (2016) afirmó que:

se sostiene en las múltiples diferencias sociológicas de quienes cohabitan el territorio colombiano. La visión de la vida, las tradiciones, el clima, las formas de intercambio, los mecanismos de adaptación al medio, los recursos naturales y algo muy importante, la importancia de la familia y su forma de concebirla. Esto está además complementado con la representación y el peso político que tienen algunas regiones en el Gobierno Nacional, lo que significa mayor presencia institucional en lo referente a los programas nacionales y por ende mayor desarrollo del capital social, mayor educación y mayores ingresos (p. 57).

Asimismo, el autor en referencia precisó que la confianza que tienen los habitantes de un territorio en la justicia es el resultado de la comunicación que existe entre el sistema judicial y ellos como ciudadanos. Además, refirió que aquellas instituciones que pertenecen al sector público construyen una buena imagen frente a la ciudadanía a través de los medios de comunicación.

En contraste, otros autores argumentaron que la percepción acerca de la justicia depende de las exigencias que las entidades estatales impongan. Según Toscano (2015),"el acceso a la jurisdicción está condicionado al cumplimiento de determinados requisitos o, en general, a la realización de alguna conducta a cargo del sujeto de derecho interesado en acudir a ella" (p. 3); mientras que López (2016) afirmó que "los factores que explican la diferencia entre los niveles de percepción se encuentran ligados más a la identidad con la institución encargada de administrar justicia y por ende a unos niveles de respeto a las instituciones" (p. 56).

Dentro de estas investigaciones es necesario retomar el estudio de La Rota, Lalinde, Santa y Uprimny (2014) que buscaba determinar la percepción que tenía la población en general sobre el acceso a la justicia. Para ello, en el trabajo citado se analizaron diversos grupos poblacionales que conviven en la sociedad, entre ellos: las personas con un tipo de discapacidad, la población LGBTI, afrocolombianos, víctimas del conflicto armado, mujeres y población en condiciones de extrema pobreza. Los autores mencionaron que "todos los encuestados respondieron acerca de su confianza en la justicia, su opinión sobre la acción de tutela, la agilidad de la justicia, los costos de acceder a ella y su percepción en torno a la honestidad de los funcionarios" (p. 149). Una de las conclusiones más importantes fue:

La percepción acerca de la justicia es poco entusiasta, aunque no desastrosa. A pesar de que alrededor de $60 \%$ tiene confianza en la justicia, existe una opinión mayoritariamente negativa acerca de su poca agilidad y de sus altos costos, una apreciación dividida acerca de la honestidad de los funcionarios y una percepción ligeramente favorable de la acción de tutela (La Rota et al., 2014, p. 156).

Por otro lado, según la investigación realizada por López (2016) se muestra que en ciudades de más de 100.000 habitantes el $20.2 \%$ no cree "nada" en el sistema judicial mientras que el $4.0 \%$ cree "mucho" en el mismo sistema, por el contrario, en las ciudades medianas y pequeñas la percepción de la justicia es un poco más favorable, ya que en promedio los que creen "nada" y los que creen "mucho" es equiparable, por ejemplo, en las ciudades medianas, entre 25.000 y 100.000 habitantes, los que no creen "nada" es de 9,4\% frente al 9.0\% que creen "mucho" y las ciudades pequeñas, de menos de 25.000 habitantes, los que no creen "nada" es del 10,8\% frente a los que creen "mucho" que es del $10.3 \%$, así las cosas 
se muestra que la percepción que tienen los colombianos respecto a la credibilidad del sistema judicial es baja.

Con los datos anteriores se puede deducir que la percepción y credibilidad frente al acceso a la administración de justicia se convierte en un limitante para acceder a la misma, ya que en el imaginario social el sistema judicial se tiene como un ente inoperante y por lo mismo, esquivo.

Otro de los factores que impiden el acceso a la administración de justicia es la congestión judicial entendido este concepto como "la acumulación real de procesos en un despacho judicial, en forma progresiva hasta llegar a un grado que desborda la posibilidad normal de su atención" (Consejo Superior de la Judicatura, 2005, p. 55). Situación que ha sido un importante impedimento para que los ciudadanos vean garantizado su derecho al acceso a la justicia. Por ejemplo, según el informe presentado por la misma entidad, en el año 2016, se evidenció que, por cada 100.000 habitantes, antes del 2016 se contaba con 10 funcionarios judiciales para apersonarse de los procesos radicados ante las diferentes jurisdicciones existentes. En el año 2016, Colombia contó con 11 funcionarios por la misma cantidad de habitantes, lo que supuso un fortalecimiento en la oferta judicial, ya que la congestión, según datos aportados por el Sistema de Información Estadístico de la Rama Judicial (SIERJU), pasó de un $45 \%$ del año 2015 a un $37 \%$ en el año 2016, sin embargo, para el año 2017 volvió a repuntar la represión de los distintos procesos en un $45 \%$, ya que anualmente hay un aumento sustancial de interposición de demandas. Todo lo anterior se puede sintetizar en las palabras de Rosado Núñez y Velásquez Pimienta (2017) quienes comentan que:

Uno de los mayores obstáculos para hacer efectiva la tutela judicial es la congestión judicial, ello supone la mora en la justicia y la lentitud de los procesos, acarreando con ello que las personas no accedan a la administración de justicia o se abstengan de hacerlo, además de la serie de trámites que implica el hecho de presentar ante el operador judicial una demanda, desde la designación del apoderado hasta los requisitos para presentarla (p. 21).
Ante este panorama, es preciso que las políticas públicas en esta materia sean priorizadas por el Gobierno Nacional, puesto que el derecho fundamental a la igualdad, al debido proceso $\mathrm{y}$ al acceso a la justicia, entre otros, son derechos de los cuales mínimamente debe gozar la ciudadanía en una verdadera democracia. Frente a esta situación, los autores plantearon propuestas de solución debido al difícil panorama que viven los grupos poblacionales considerados vulnerables en la sociedad, "también nos referimos a la necesidad de incentivar el arreglo directo, sobre todo en las poblaciones en extrema pobreza y con discapacidad, y de monitorear en mayor medida los servicios de justicia provistos por autoridades judiciales, administrativas y particulares" (La Rota et al., 2014, p. 401).

El Estado colombiano, para garantizar el derecho fundamental de acceso a la administración de justicia, promulgó el Decreto 2158 de 1948, que sirvió como base para la edificación de lo que hoy se conoce como los MASC. Desde entonces estos mecanismos han sido significativos para fortalecer la convivencia social y el restablecimiento de los derechos fundamentales, más allá de la descongestión judicial; y surgieron dentro del derecho laboral, en busca de medios alternativos para dirimir las problemáticas suscitadas en esta materia, como lo planteó González (s.f.) como se citó en Campo (2016), quien indicó que fue a partir del Código Procesal del Trabajo (Decreto 2158 del 24 de junio de 1948) que se habló por primera vez de la conciliación sin necesidad de acudir ante un juez como forma alternativa para resolver directamente los conflictos existentes entre los empleados y los empleadores.

Posteriormente, en 1970, se expidió en materia normativa el Código de Procedimiento Civil (Decreto 1400 de 1970), en el cual se enfatizó en la conciliación para resolver las controversias de mínima cuantía y el proceso verbal sumario. Más tarde, se expidió el Decreto 2303 de 1989 referente a la conciliación en materia agraria, simultáneamente a la publicación de un fallo del Tribunal Supremo en el que abordó la conciliación en los siguientes términos:

Nuestra Corte Suprema de Justicia en Sentencia de 31 de marzo de 1971, define la conciliación como acuerdo amigable celebrado entre las partes, con la intervención 
de funcionarios competentes quien lo dirige, impulsa, controla y aprueba; quien pone fin de manera total o parcial a una diferencia y tiene efectos o fuerza de cosas juzgadas (Campo, 2016, p. 6).

De igual forma, el arbitraje también ha sido protagonista en el ordenamiento jurídico colombiano. Por ejemplo, en la Ley 105 de 1890 ya se hablaba del juicio de arbitramento (primera denominación que se le dio al arbitraje) para referirse al aspecto procedimental de la figura. Y en relación con la jurisprudencia de la época, la Sala de Casación Civil de la Corte Suprema de Justicia, en Sentencia del 25 de noviembre de 1895, estudió el caso de dos comerciantes que celebraron un contrato de sociedad, en el cual incluyeron una cláusula compromisoria que fue declarada ineficaz y nula por el Tribunal Supremo al no tener antecedentes normativos en ese tema al momento de su creación. Sobre este caso Cardozo (2015) mencionó que:

la Corte resaltó que la cláusula compromisoria estaba autorizada en las normas del Estado Soberano de Cundinamarca, pero no en las normas nacionales reconocidas como tales por la Ley 57 de 1887 e indicó que esta autorización solo se volvió a conceder en la Ley 105 de 1890 y el contrato de sociedad había sido celebrado el día 1ํ de octubre de 1887 (p. 29).

Actualmente, Colombia cuenta con una legislación y jurisprudencia abundante en materia de alternatividad respecto a los mecanismos para solucionar las controversias en el país, lo cual evidencia el desarrollo que ha tenido el derecho fundamental de acceso a la administración de justicia en Colombia desde sus orígenes. Es así como en el país, con la expedición de la Constitución Política de 1991, también denominada la Constitución de los Derechos Humanos, se ha buscado garantizar los derechos de los ciudadanos y exigir el cumplimiento de los deberes tanto al individuo como a la sociedad. De hecho,

La Constitución Política de Colombia, pese a no entrar de manera directa a regular la conciliación como un aspecto valido para la administración de justicia de una forma pronta, es importante advertir que la misma se encuentra intrínseca en los artículos 22
116 de nuestra carta magna, al referirse a la paz como un derecho fundamental y el deber que le asiste al Estado de garantizar la paz y la sana convivencia entre sus administrados, donde los Mecanismos Alternativos de Solución de Conflictos "MASC" han sido de gran importancia a la hora de conjurar situaciones de litigio y antes de este (Campo, 2016, p. 12).

La creación de los MASC responde al propósito de contar con un recurso que permitiera lograr la descongestión judicial en el país, entendiendo la congestión como "la acumulación real de procesos en un despacho judicial, en forma progresiva hasta llegar a un grado que desborda la posibilidad normal de su atención" (Consejo Superior de la Judicatura., 2005, p. 55). Situación que ha sido un importante impedimento para que los ciudadanos vean garantizado su derecho al acceso a la justicia.

Es destacable la labor realizada por el constituyente en la actual Constitución Política de Colombia, que facultó a los ciudadanos para que participaran en la solución de sus propios conflictos y empoderó a los particulares para que, a la par del Estado, administraran justicia, convirtiéndose en un camino para lograr la descongestión en el sistema judicial en cuanto no se sumen más procesos para que sean atendidos por el operador judicial. Siguiendo a Illera (2017) "el aporte de la carta política de 1991 consistió en reglamentar por primera vez, la posibilidad de que los particulares puedan administrar justicia como conciliadores o árbitros" (p. 6) y agrega: "Colombia fue el primer país en Latinoamérica que estableció de manera constitucional el desarrollo de los mismos" (p. 188).

Sin embargo, hay posturas contrarias que se oponen a la constitucionalización de los MASC en cuanto consideran que, en muchos casos, la solución a estos conflictos no depende necesariamente del Estado, ejemplo de eso se encuentra en Osorio (2012) quien considera que "se ha enmarañado innecesariamente al arbitraje (e incluso a otros MASC), malogrando su finalidad e impidiendo que se pueda adecuar a estándares internacionales y que progrese según las necesidades del tiempo" (p. 11).

Contrario a los planteamientos de Osorio, pero en concordancia con los fines esenciales del Estado, se ha insistido en las bondades que 
tienen estas herramientas y por ello defienden su existencia e institucionalización. Una de estas voces es la de Illera (2017), quien afirma que los MASC:

$$
\begin{aligned}
& \text { Ayudan a mitigar la conflictividad } \\
& \text { fortaleciendo la convivencia en el } \\
& \text { cumplimiento de la función jurisdiccional, } \\
& \text { como un modelo de justicia alternativa y } \\
& \text { complementaria más no sustitutiva de la } \\
& \text { justicia estatal formal. Los operadores de } \\
& \text { estas figuras (conciliadores, árbitros), no } \\
& \text { son servidores públicos, son particulares } \\
& \text { que realizan una función pública de manera } \\
& \text { temporal y transitoria, cuyas actuaciones } \\
& \text { están reglamentadas en la ley (pp. 4-5). }
\end{aligned}
$$

La pluralidad de opiniones que se tienen frente a este tema es destacable. Algunos autores han percibido la existencia de estas herramientas de forma positiva porque consideran que su invención representa una oportunidad para el desarrollo de la participación ciudadana, así como también un apoyo para que el Estado supere la congestión judicial y, desde luego, un alivio frente a las dificultades de la justicia formal, pues el gran problema que enfrenta la justicia ordinaria es la reducida capacidad que tiene para atender todos los conflictos, necesidad frente a la cual han surgido estos mecanismos alternativos (Illera, 2017). Del mismo modo, para García y Ramírez (2010) la implementación de los MASC va más allá de ser un soporte para la administración de justicia, pues consideraron que es preocupante la no injerencia del Estado para reconocer los presupuestos que la carta superior le ordena a este. Razón que los lleva a afirmar que:

a partir de la Constitución Política de 1991 se le otorgó a los particulares la facultad de administrar justicia de manera transitoria, el aparato de justicia se escuda en los MASC que, principalmente, (aunque para sus efectos debe ser sumada la Jurisdicción Especial de Paz), descongestionan el aparato estatal y fomentan la participación democrática, disimulando la precariedad de la administración de justicia formal y reclamando luego, para sí misma, la legitimidad y credibilidad que aquellos crean, dejando en un segundo plano la problemática real del acceso a la administración de justicia formal (p. 36).
De forma similar, para Tavera (2012), "el auge de estos mecanismos exógenos de gestión del conflicto coincide con la implosión de los sistemas judiciales y su incapacidad para asumir la creciente e imparable demanda de justicia" (p. 281).

Ahora bien, al observar el panorama actual de la justicia en Colombia se puede concluir que en el país existen dos opciones de acceso a esta: 1) la formal que es estatal, y 2) la informal que tiene el carácter de privada. De allí que Illera (2017) resaltara la urgencia por que el Estado garantice la prestación del servicio de manera adecuada; pues, de lo contrario, se continuará observando la justicia privada o informal como sustitutiva de la justicia pública o formal $\mathrm{y}$, en consecuencia, los ciudadanos tendrán una percepción negativa respecto a las alternativas que ofrece el Estado y aumentará su desconfianza hacia la justicia formal que consideran carente de transparencia y efectividad en los procesos.

\section{EL ARBITRAJE SOCIAL, UN MECANISMO DE JUSTICIA ALTERNATIVA ATRACTIVO PARA LAS MIPYMES}

Desde sus orígenes el arbitraje se ha caracterizado por ser un mecanismo utilizado, principalmente por los comerciantes para dirimir sus controversias. Según Zappalá (2010), este concepto se remonta a la época griega, en la cual se designaban sabios de diferentes tribus, a quienes se les encomendaba la labor de resolver los conflictos de la comunidad. Con el transcurrir del tiempo, estas prácticas fueron adoptadas por el derecho romano que, ante el aumento de las actividades comerciales, tanto marítimas como terrestres, se vio obligado a acudir a esta instancia; asimismo, en el Medioevo el derecho comercial se valió de la figura del arbitraje para resolver los conflictos mercantiles entre comerciantes (Villalba y Moscoso, 2008, p. 167). Otros autores manifestaron que el arbitraje siempre ha estado inmerso en las relaciones interpersonales, puesto que "la figura del arbitraje evolucionó junto a las sociedades humanas, sirviendo como apoyo en el crecimiento de los grupos humanos, en el sentido de aportar sus características en la solución de los conflictos que haya surgido en estos" (Rueda, 2015, p. 48). 
En el contexto nacional actual, se han atribuido múltiples definiciones a esta institución (el arbitraje) en la doctrina colombiana. Una de estas aproximaciones se refiere al arbitraje como un instrumento para la solución de conflictos mediada por un tercero, es decir, el árbitro (Perea, 2013). Por otra parte, se entiende como una figura independiente dentro del ordenamiento jurídico que centra su atención en la resolución de controversias atendidas por una persona especializada en la materia (Pérez, 2017), mientras que el Ministerio de Justicia y del Derecho lo establece como un "mecanismo alternativo de solución de conflictos mediante el cual las partes defieren a árbitros la solución de una controversia relativa a asuntos de libre disposición o aquellos que la ley autorice". Aunado a las anteriores definiciones, Moure (2019) coincide en cuanto a la libre disponibilidad de la materia que se les encomienda a los particulares elegidos para intervenir como jueces.

Desde otra perspectiva, se retomaron los elementos citados y, a su vez, se profundizaron en otras características que hacen parte del arbitraje, puntualizando en elementos fundamentales como la voluntariedad de las partes y el tipo de decisión que profieren los árbitros, lo cual es expresado así:

La facultad que tienen los particulares en ejercicio de la autonomía de su voluntad, para decidir no acudir a la jurisdicción administrada por el Estado, sino por el contrario habilitar a unos particulares denominados árbitros, para resolver de forma definitiva a través de un laudo-providencia equivalente a una sentencia judicial que emite un juez ordinario, por medio de un negocio jurídico denominado pacto arbitral (Pineda, 2017, p. 34).

Si se observa en detalle esta línea argumental, el pacto arbitral constituye el fundamento del arbitraje y, asimismo, representa la autonomía de las partes que voluntariamente deciden confiar su controversia, actual (compromiso) o futura (cláusula compromisoria) al árbitro. Este es un particular, experto en determinada materia, quien se convierte en un actor protagónico al aplicar su experticia en el caso y proferir un fallo. Según Perea (2013), al ser predecible el sentido del veredicto, las partes reconocen los criterios del árbitro, por lo que tienden a acudir a él para dirimir sus controversias; en consecuencia, el árbitro tiene un nivel de exigencia mayor comparada con la de un juez de la justicia ordinaria, dado que, al ser un particular que administra justicia de manera temporal, es juzgado en tal condición y simultáneamente con el régimen de los funcionarios judiciales (Salcedo, 2010).

En cuanto a los elementos primordiales del arbitraje, Pérez (2017) identificó algunas características que diferencian al arbitraje de los demás mecanismos y de la justicia estatal. Entre ellas, señaló que este mecanismo es:

Heterocompositivo en atención a que la controversia es sometida a la decisión de un tercero imparcial y calificado; convencional ya que es fundamental que las dos partes estén de acuerdo en que su inconveniente sea sometido a la disposición de un tribunal de arbitramento; temporal porque el tribunal de arbitramento se integra para atender $y$ dirimir solamente determinada controversia; revestido de juridicidad por tener todas las garantías $\mathrm{y}$ principios constitucionales $\mathrm{y}$ legales (p. 277).

Este carácter heterocompositivo, convencional, temporal y revestido de juridicidad del arbitraje lo hace atractivo no solo para los ciudadanos, sino además para las mipymes, quienes deciden confiar sus disputas en este tipo de mecanismos (Rodríguez, 2012). Además, la celeridad se convierte en una fortaleza comparada con la ineficacia que ha mostrado la justicia ordinaria para la resolución de los conflictos, como lo reiteraron el Consejo Superior de la Judicatura y la Corporación Excelencia en la Justicia (2016) al indicar que en los procesos judiciales los jueces se amparan en la congestión judicial para incumplir los tiempos procesales que les impone la ley.

Al constitucionalizarse el arbitraje, se expidieron varias normas que sistematizaron algunos aspectos de esta figura, entre ellas: la Ley 23 de 1991, el Decreto Ley 2651 de 1991, la Ley 80 de 1993, la Ley 270 de 1996, la Ley 446 de 1998. Por último, con la Ley 1563 del 2012 se expidió el Estatuto de Arbitraje Nacional e Internacional, que dotó a la institución arbitral de mayor seguridad jurídica, lo cual, junto con las características mencionadas, lo convierten en una opción atractiva para los empresarios. 
Sin embargo, se ha reconocido que, pese al prestigio que tiene el arbitraje, también presenta diversos inconvenientes. Ejemplos de ellos son: que no puede ser usado para solucionar todo tipo de controversias y, tampoco lo puede realizar cualquier persona, situación a la que se le conoce como arbitrabilidad. En palabras de Ortegón (2018):

Cuando la cuestión de arbitrabilidad responde a la materia que va a ser objeto del tribunal, se trata entonces de un problema de arbitrabilidad objetiva. Por el contrario, si la cuestión de la arbitrabilidad responde a los sujetos para quienes es obligatoria la decisión del tribunal, entonces se está ante un caso de arbitrabilidad subjetiva (p. 183).

Lo anterior significa que el arbitraje obedece a los criterios de competencia del árbitro y de capacidad jurídica por las partes. Dicho de otra forma, un asunto que no sea transigible o de libre disposición por los sujetos en conflicto está exento de la aplicación de un laudo arbitral. De otro modo, se coincide con Naizir (2019) en que la arbitrabilidad objetiva debe ser dinámica y evolucionar junto con las necesidades de cada territorio a través de la legislación y la jurisprudencia. Otros casos que no se pueden tramitar a través del arbitraje son:

(i) los asuntos relacionados con el estado civil de las personas, (ii) asuntos laborales sobre derechos ciertos e indiscutibles, (iii) la impugnación de actos o decisiones de la asamblea de accionistas o juntas de socio en las sociedades comerciales, entre otros, deben ser sometidos a la jurisdicción ordinaria, pues no son asuntos sujetos de transacción (Restrepo, 2014, p. 72).

Por otro lado, dentro de las clases que componen el arbitraje, se encuentra el arbitraje social, el cual fue ideado con la finalidad de brindar una posibilidad gratuita para la resolución de conflictos, en cuanto que si bien, la prestación del servicio está disponible para cualquier ciudadano es necesario que la cuantía no supere los 40 SMLMV (Ley 1563, 2012, art. 117), ya que este monto se considera no relevante para ser resuelto por la justicia formal.

Adicionalmente, este tipo de arbitraje establece que el trámite se adelante a través de un solo árbitro, y señala que no es necesario acudir al tribunal de arbitramento mediante la representación de un apoderado judicial. Así mismo, la norma estipula que este mecanismo se oferte en jornadas y no como un servicio permanente, dándole la facultad a los centros de arbitraje, a nivel nacional, de definir su propio procedimiento, lo que genera un vacío legal, situación que llevó a que las cámaras de comercio establecieran el procedimiento para la ejecución de este tipo de arbitraje; por ejemplo, la Cámara de Comercio de Bogotá expidió el "Reglamento de Procedimiento de Arbitraje Mipymes y Arbitraje Social", subdividiendo en dos categorías el arbitraje social y permitiendo que el arbitraje mipymes ${ }^{1}$ tuviese un enfoque autónomo con requisitos exclusivos para los pequeños empresarios (Benneti, 2018). Así las cosas, la CCB definió el arbitraje mipymes como un servicio que presta el Centro de Arbitraje y Conciliación -CACen el que se pretende resolver conflictos en los que esté implicada al menos una empresa mipyme (art. 4.1). No obstante, al actualizarse este reglamento en el año 2017, se modificó el nombre a Procedimiento de Arbitraje Social, unificando el arbitraje mipymes con el arbitraje social, propuesta que hizo anticipadamente Sebastián Bernal Garavito en la Tertulia Perspectivas del Arbitraje Social en Colombia, con la finalidad de simplificar los procesos (CCB, 2017b, 1h30m).

Por último, es destacable la opinión que tiene Torres e Iregui (2020) sobre el arbitraje social, ya que lo presentan como una alternativa muy pertinente para los fines de reparación que persiguen la acción constitucional de grupo.

\section{LAS CÁMARAS DE COMERCIO Y LA RESPONSABILIDAD SOCIAL EMPRESARIAL HACIA UNA GESTIÓN DE PAZ}

El rol que desempeñan las cámaras de comercio en la sociedad colombiana es de resaltar, dado que, tal y como se determinó en el Código de Comercio (Decreto 410, 1971, art 86), atienden todo lo relacionado a los asuntos mercantiles, la defensa de los intereses generales del gremio de los empresarios y, a su vez, están comprometidas con el fomento e impulso de los métodos

1. Es importante precisar que mediante la Ley 590 de 2000 se establecieron, haciendo referencia a las micro, pequeñas y medianas empresas, de acuerdo con la categorización, la cantidad de empleados y el valor total de los activos. 
alternativos de solución de controversias. Cabe aclarar que estos intentan resolver los inconvenientes que surgen con proveedores, deudores, clientes, otras empresas y demás situaciones que están a la orden del día. Estas entidades al crear los centros de conciliación y arbitraje han logrado disuadir el escalonamiento de los conflictos, lo que quiere decir que los ciudadanos han encontrado en los MASC una oportunidad para finiquitar sus controversias, y evitar que estos se conviertan en una necesidad jurídica cuando presentan problemas en el acceso a la justicia (Peña, 2018).

Dentro de las funciones anteriormente descritas, que la ley estableció para las cámaras de comercio, se observa que la concerniente al impulso de los MASC está directamente relacionada con la RSE, este principio se puede entender como el compromiso que tienen las organizaciones frente a los impactos que se ocasionan en las comunidades y en el medio ambiente para de esa manera contribuir al desarrollo sostenible (ISO 26000, 2010), así mismo, se propicia dentro de la toma de conciencia para disminuir la brecha entre la acción social del Estado y la del sector empresarial generando nuevas maneras de preocupación por el bienestar comunitario (Mata, 2010).

Este escenario (de la RSE) se transforma en una oportunidad para que las cámaras de comercio, a través de los empresarios y sus asociaciones, participen en los procesos de reconstrucción del tejido jurídico y social mediante la generación de iniciativas que permitan unificar los caminos hacia la paz, pues no solo se trata de reunir esfuerzos pensando en la rentabilidad únicamente, sino en el interés común que la sociedad les reclama para que sea restituida en beneficios colectivos (Grasa, Carvajalino y Duque, 2019). En concordancia con esta responsabilidad, Ravina-Ripoll et al. (2020) hablaron sobre la importancia de:

mencionar también que en el país se han desaᄀrrollado diferentes iniciativas para apoyar la construcción de paz tanto fuera como dentro de las empresas, es el caso del proyecto Construcción de paz desde Confecámaras y las Cámaras de Comer $\neg$ cio de Colombia el cual fue elaborado gracias a una alianza entre la Fundación Ideas para la Paz, Confecámaras (Confederación de Cámaras de Colombia) y la Cámara de Comercio de
Bogotá, buscando proponer una hoja de ruta estratégica para que dichas organizaciones fortalezcan su rol como dinamizadoras de la reconᄀciliación y la convivencia nacional ( $\mathrm{p}$. 305).

Así las cosas, es evidente que la aplicación de la RSE, que en este caso han promovido las cámaras de comercio, apuntan al mejoramiento de las comunidades, pero además del fortalecimiento empresarial en el país.

Dentro de Bogotá y la región se encuentra la $\mathrm{CCB}^{2}$ como una entidad que en el ejercicio de su RSE promueve los MASC a través del CAC, impulsando programas sociales, gratuitos, que impactan en los sectores: educativo, gracias al programa de convivencia escolar HERMES; y comunitario, por medio de los Centros de Convivencia Empresarial, antes denominadas Sedes Comunitarias, que propician la conciliación en equidad, en relación a la conciliación en derecho promueve las jornadas denominadas Conciliatón y en cuanto al arbitraje, este se logra a través del arbitraje social que se encarga de los conflictos que no superan los 40 SMLMV.

A manera de reflexión, se considera que la intervención de las cámaras de comercio en la construcción de paz es fundamental y necesaria, especialmente en la medida en que estas son multiplicadoras de la convivencia pacífica en sus áreas de influencia, mediante el impulso que le dan a los MASC, lo que impacta positivamente en la calidad de vida de los habitantes y ayuda a mitigar la brecha de desigualdad y de violencia.

A pesar de lo anterior, como lo destacó Ruíz (2013), son escasos los estudios en la literatura colombiana sobre el efecto que tiene la responsabilidad social de las empresas frente a la solución de los problemas de la comunidad en la que se desenvuelve y en la defensa del medio ambiente.

2. Se centra la atención en la CCB porque al realizar una revisión documental acerca de la figura del arbitraje en Colombia, se identificó que la Cámara de Comercio de Bogotá es la institución que mayor producción investigativa y documental tiene en el tema 


\section{REVISIÓN DE LAUDOS ARBITRALES PARA MIPYMES PROFERIDOS POR LA CÁMARA DE COMERCIO DE BOGOTÁ ENTRE LOS AÑOS 2009 Y 2014}

En el estudio realizado en el año 2017 por la CCB y el Ministerio de Justicia y del Derecho al arbitraje en el territorio nacional se evidenció que, pese a los esfuerzos realizados por entidades públicas y privadas en su desarrollo, la presencia de centros de arbitraje es escasa. Según esto, la mayoría de éstos concentran su operación en las principales ciudades, entre ellos destacan los pertenecientes a la Superintendencia de Sociedades, la CCB, Cámara de Comercio de Medellín, Cámara de Comercio de Cali y Cámara de Comercio de Cartagena. "De la misma forma, algunos de los directores de los centros recomiendan mayor presencia y soporte en la operación del arbitraje por parte del Ministerio de Justicia y del Derecho además de la función de inspección, control y vigilancia" (CCB, 2017b, p. 193).

Al centrar la atención en la CCB, dentro de la RSE que le corresponde, ésta impulsa programas sociales que impactan en los sectores educativo, comunitario y empresarial a través del CAC. Además, en atención a lo señalado en el artículo 117 del Estatuto Arbitral, entre los años 2009 y 2016 ésta realizó Jornadas Gratuitas de Arbitraje para Mipymes. De este modo, el CAC (2014) disponía de un Reglamento de Procedimiento de Arbitraje Mipymes y de Arbitraje Social; sin embargo, en la actualidad el arbitraje mipymes hace parte del social.

Es importante subrayar que, en un intervalo de cinco años (2009-2014) el CAC de la CCB logró contribuir en la resolución de conflictos de 450 empresas catalogadas como mipymes. Dentro de estas cifras, en el año 2014 con el Centro de Conciliación y Arbitraje Empresarial de la Superintendencia de Sociedades, se celebró un Convenio de Apoyo Interinstitucional con el propósito de fortalecer el servicio de arbitraje en el sector empresarial (CCB, 2014).

En concordancia con lo manifestado, respecto de la RSE de la CCB y dando respuesta al problema jurídico planteado, se consideró importante incluir en el presente artículo la revisión de los 10 laudos arbitrales, resultado de las Jornadas Gratuitas de Arbitraje Mipymes, para demostrar el compromiso de la entidad al contribuir en la solución pacífica de los conflictos de las mipymes, como una forma de acceso a la administración de justicia dado que encontraron en el arbitraje mipymes, hoy social, una manera de hablar de las controversias existentes entre ellas, mediante un procedimiento rápido y gratuito, ante un árbitro y sin necesidad de un apoderado judicial.

La revisión de los laudos describe la identificación de la tipología del conflicto, el problema jurídico debatido, el sentido del fallo del árbitro y el tiempo transcurrido entre la fecha de radicación de la demanda y la fecha de emisión del laudo. Es interesante observar la variedad de asuntos contractuales que son objeto de debate en cada uno de los laudos, así como la especialidad en la respectiva materia con la que se decidieron.

Inicialmente, se encontró el laudo del 11 de diciembre de 2009 (Cámara de Comercio de Bogotá, árbitro Carlos Antonio Espinosa Pérez, 2009), el cual hacía referencia al derecho de asociación que defendía Rubén Darío Pineda Torres, demandante, frente a Asjoyería Bogotá, Asociación de joyería y actividades afines de Bogotá y Cundinamarca, demandada. En el curso de la litis se demostró que la exclusión del señor Pineda fue ilegal, toda vez que el artículo 51, numeral 6 de los estatutos de la Asociación le otorgó únicamente esa facultad a la Junta Directiva, mas no a la Asamblea General. Además, la exclusión no se fundamentó en alguna de las causales de los estatutos establecidas en el artículo 15 , numerales 4 y 5 , desconociendo de este modo los derechos al debido proceso y a la defensa del demandante. Entre el día de instauración de la demanda, 26 de septiembre de 2009, y la emisión de fallo, 11 de diciembre de 2009, transcurrieron 2 meses y 16 días calendario.

Por su parte, el caso de Makroplásticos Ltda. contra Arte y Diseño Modular J\&R Ltda. pretendía arbitrar la discrepancia sobre un contrato de compra venta cuyo objeto era el abastecimiento de mercancías para la floricultura. El debate radicó en indagar si se reunieron los requisitos de un contrato de compraventa de mercancías o, por el contrario, el de un contrato de suministro. Teniendo en cuenta que la parte demandada no compareció a la diligencia de instalación del Tribunal de Arbitramento, se le designó curador ad litem, quien se opuso a las pretensiones y formuló las siguientes excepciones: compensación, prescripción y nulidad relativa sustancial. No 
obstante, el árbitro no las aprobó, puesto que la empresa demandante no debía nada a la empresa demandada; dentro de este caso, no hubo prescripción de conformidad con lo establecido en el artículo 882 del Código de Comercio, donde el acreedor prefirió usar la condición resolutoria derivada de la factura cambiaria impagada y, por consiguiente, no existió nulidad relativa porque el contrato de compraventa, título valor, reunía todos los requisitos legales (Cámara de Comercio de Bogotá, árbitro Roberto Aguilar Díaz, 2010). Entre el día de radicación de la demanda, 28 de noviembre de 2009 y el proferimiento de la sentencia, 14 de abril de 2010, pasaron 4 meses y 17 días calendario.

Por otro lado, en un caso relativo a un contrato de transporte especial de personas celebrado entre la empresa de transportes Megavans S.A. (accionante) y la organización de viajes y turismo EU-Orvitur Ltda. (accionada), la controversia versaba sobre la existencia o inexistencia del contrato mencionado. En el desarrollo de la discusión, la empresa demandada solicitó la declaración de invalidez del negocio jurídico, contrato/planilla No. 3236 como pretensión principal $y$, a su vez, como subsidiaria, la declaración de su nulidad. Sin embargo, se evidenció la existencia del contrato de transporte entre las partes, por lo que se declaró el incumplimiento de la parte convocada por no pago (Cámara de Comercio de Bogotá, árbitro Juan Pablo Riveros Lara, 2011). Entre el día de instauración de la demanda, 2 de noviembre de 2010, y la emisión del laudo, 4 de febrero de 2011, transcurrieron 3 meses y 3 días calendario.

Asimismo, el 5 de agosto de 2011 la CCB hizo un pronunciamiento sobre el enfrentamiento que hubo entre la Sociedad Campo Elías Gamboa S. A. S. y Alfagres S. A. por un contrato de materiales para la elaboración de unas gradas en concreto en el Centro Comercial Sancancio ubicado en la cuidad de Manizales. Una vez terminado el conflicto, la CCB declaró que existió una obligación clara, expresa y exigible a favor de la convocante contra la convocada, por tanto, declaró que hubo incumplimiento por el no pago de la factura 608 del 6 de julio de 2009.

Además, la CCB declaró no probada la excepción de mérito de contrato no cumplido formulada por Alfagres S. A., y negó todas las pretensiones presentadas en la demanda de reconvención: solicitud de declaratoria del incumplimiento del contrato, devolución del precio que pagó por los materiales de las gradas, pago de perjuicios materiales, y la condena a la convocante al pago de las costas y los gastos del arbitraje. Esta fue la decisión a la que llegó el árbitro teniendo en cuenta únicamente el concepto dado por el perito que hizo el análisis del estado en que la Sociedad Campo Elías Gamboa S. A. S. entregó la obra (Cámara de Comercio de Bogotá, árbitro Iván Humberto Cifuentes Albadan, 2011). Conviene aclarar que entre el día de radicación de la demanda (1 de septiembre de 2010) y el proferimiento de la decisión (5 de agosto de 2011) transcurrieron 11 meses y 5 días calendario.

La Cámara también se ocupó de un caso relacionado con un contrato de gestión para obtener una beca deportiva. Se trata del proceso iniciado por Daniel Felipe Cardona Aranda contra Collegiate sports of America S. A. S. En este caso, el Tribunal le dio la razón a la parte demandada al considerar que, pese a la lesión física que sufrió el señor Cardona en el pie derecho el 24 de mayo de 2011, el contrato seguía vigente en concordancia con lo establecido en el artículo 1602 del Código Civil. Así pues, declaró probada la excepción de falta de causa para demandar toda vez que el demandante no logró demostrar su imposibilidad de dar cumplimiento al contrato y denegó las pretensiones consignadas en el libelo de la demanda, esto es, la declaratoria de terminación del contrato y el reembolso del dinero (Cámara de Comercio de Bogotá, árbitro Sergio Muñoz Laverde, 2012). Entre el día de la presentación de la solicitud de convocatoria (10 de noviembre de 2011) y la emisión del fallo (27 de marzo de 2012) pasaron 4 meses y 18 días calendario.

Además, se cita en este apartado la decisión relacionada con la responsabilidad civil contractual derivada de un contrato de prestación de servicios de apoyo logístico para un evento de 15 años, el cual tendría lugar el 23 de febrero del 2013. El proceso fue iniciado por María Lucero Quintero Arias, madre de la afectada, contra Jennifer Reina Rojas, propietaria del establecimiento de comercio Casa de Modas y Recepciones Jenny Jhon's. El árbitro decidió declarar el incumplimiento del contrato por parte de la demandada, pese a que la contratista hizo entrega de la totalidad de lo convenido, no lo hizo con la calidad acordada. Dentro de esta situación, 
se condenó al pago de daños materiales y morales como indemnización por los daños y perjuicios ocasionados, afirmando lo siguiente:

Esa actuación de la convocada no solo causó un daño material a la demandante consistente en no recibir la contraprestación pactada por lo pagado, sino además un daño moral pues es claro que quien con tanto esmero se dedica a programar una fiesta como la que contrató la señora Quintero para la celebración de los 15 años de su hija, pone todas sus esperanzas en ese evento y al verlo estropeado genera una gran tristeza, más cuando ve que los sueños de su hija y los propios se frustran (Cámara de Comercio de Bogotá, árbitro Antonio Pabón Santander, 2013).

Este caso deja entrever la celeridad del arbitraje frente al proceso judicial, teniendo en cuenta que el proceso inició el 10 de septiembre del 2013 y finalizó el 2 de diciembre del mismo año. Esto indica que el conflicto se atendió en el término de 2 meses y 23 días calendario.

Dando continuidad a la revisión de los laudos arbitrales, la CCB intervino en un caso que tenía que ver con un contrato de prestación de servicios de asesoría inmobiliaria celebrado entre Ana Cecilia Serna Román y los asesores inmobiliarios de Acseim Ltda. La demandante contrató a la inmobiliaria con la finalidad de adquirir un inmueble sometido a remate, sin embargo, la adjudicación no se dio pese a la compra que hizo de un derecho litigioso, por sugerencia de la empresa contratista. La demanda de la señora Serna a la contraparte se dio a través de apoderada judicial, y en el curso del proceso arbitral se determinó que el objeto del contrato iba más allá de ser una mera asesoría para comprar un crédito o un derecho litigioso, puesto que la compra de este representaba un medio para la adquisición de una vivienda. Sumado a esto, en el clausulado la convocada se había comprometido a adelantar todas las actividades necesarias para lograr la entrega real y material del bien, por lo que se declaró incumplimiento del contrato y se accedió a las demás pretensiones de la demandante (Cámara de Comercio de Bogotá, árbitro Alberto Zuleta Londoño, 2011). Cabe aclarar que, entre el día de radicación de la demanda (5 de agosto de 2011) y el proferimiento de la decisión (15 de diciembre de 2011) transcurrieron 4 meses y 11 días calendario.
Ahora bien, en el siguiente fallo, la CCB disipó el conflicto generado entre Bag's King Ltda. en acuerdo de reestructuración y Master Química Ltda., quien actuó con abogado. La disputa estuvo relacionada con la celebración de un contrato de distribución de chalecos de alta visibilidad para motociclistas, fundamentado en la expectativa de aventajar la aprobación de un proyecto de ley en el Congreso que exigiría dichas características, por tanto, ambas partes asumían el riesgo que generaría la no aprobación. Al materializarse la situación planteada las mipymes recurrieron al arbitraje, pero se concluyó que no hubo incumplimiento del contrato por ninguna de las partes al operar la frustración del fin del contrato, es decir, la destrucción de la base objetiva del negocio; además, se eximió del pago de perjuicios, lo que no dio lugar a indemnizaciones ni restituciones mutuas (Cámara de Comercio de Bogotá, árbitro Jorge Pinzón Sánchez, 2011). Entre el día de instauración de la demanda (10 de noviembre de 2010) y la emisión de la sentencia (25 de marzo de 2011) transcurrieron 4 meses y 16 días calendario.

Por otra parte, en el laudo del 25 de enero de 2012 se demostró el accionar limitado del árbitro que, en su rol de juez interpretó el contrato en busca de la verdadera voluntad de las partes, pero no le estaba permitido modificar la demanda ni las pretensiones. En este caso, Watchtower Security Ltda. demandó al Conjunto Residencial Dardanelos II P.H., que actuó con representante judicial por el incumplimiento del contrato de prestación de servicios de vigilancia y por la falta de pago de las prórrogas realizadas, oponiéndose la propiedad horizontal a las pretensiones y formulando por su parte excepciones de mérito. En primer momento, el sentido del fallo negó la pretensión de la demanda por la ausencia de sentido lógico, lo que impidió al Tribunal pronunciarse de fondo, además condenó al conjunto al pago de la cláusula penal por incumplimiento del contrato; sin embargo, resulta curioso que ninguna de las partes solicitó la terminación del contrato (Cámara de Comercio de Bogotá, árbitro Carlos Antonio Espinosa Pérez, 2012). Entre el día de radicación de la demanda (8 de septiembre de 2011) y el proferimiento del laudo (25 de enero de 2012) transcurrieron 4 meses y 18 días calendario.

El último laudo revisado trata de un contrato de intermediación comercial celebrado entre 
Jesús Jaime Ayala Estrada, que participó con apoderado, y Fivecon Group S. A. S. En desarrollo de dicho contrato, el convocante autorizó a la empresa convocada a gestionar ante una entidad financiera la obtención de un crédito para adquirir un vehículo con las características descritas en la cláusula segunda, con fines de explotación comercial. El árbitro no encontró en el expediente prueba alguna de la actuación de la empresa que estuviera encaminada al cumplimiento del objeto contractual. Igualmente, la ausencia total de Fivecon Group S. A. S. en el trámite arbitral impidió desvirtuar los indicios de incumplimiento contractual, declarando la terminación del contrato por inobservancia de las obligaciones contraídas y accedió a las demás pretensiones de índole económico del demandante (Cámara de Comercio de Bogotá, árbitro Fernando Pabón Santander, 2014). Entre el día de presentación de la solicitud de convocatoria (17 de octubre de 2013) y la emisión del fallo (5 de febrero de 2014) pasaron 3 meses y 19 días calendario.

Como se puede observar en los casos examinados, además de la gratuidad, uno de los grandes beneficios del arbitraje social consiste en la celeridad en la que fueron tramitados, según la tipología contractual, teniendo como el más expedito el fallo del caso Rubén Darío Pineda Torres contra Asjoyería que se gestionó en 76 días, frente al que más duración presentó que fue el de Sociedad Campo Elías Gamboa S. A. S. contra Alfagres S. A. que se tardó 335 días en resolverse. $\mathrm{Si}$ estos datos se contrastan con estadísticas de los procesos judiciales para la misma época, se encuentra que en el documento Resultados del estudio de tiempos procesales (2016), la duración de los procesos civiles, en términos de días, oscila en: Verbal 548, Ordinario1228, Jurisdicción voluntaria 399, Abreviado 542, Ejecutivo singular 598, Ejecutivo mixto 1078, Ejecutivo prendario 848 y Ejecutivo hipotecario 670. Según el estudio observado, los factores que influyen en la congestión judicial se relacionan con la categoría de juez que atiende el caso, la cuantía que se discute, la región del país objeto de análisis, las interrupciones procesales por movimientos judiciales entre juzgados, la asignación de acciones constitucionales en los despachos judiciales y el procedimiento aplicable al caso, que para el año 2008 correspondía al Código de Procedimiento Civil. Lo anterior permite inferir la utilidad que genera el arbitraje social sobremanera para el ciudadano que requiere una solución pronta para sus controversias y que no la podría hallar, fácilmente, ante un despacho judicial.

\section{CONCLUSIONES}

El estudio de las necesidades jurídicas insatisfechas determinó que se debe incentivar el arreglo directo en la población económicamente vulnerable y con discapacidad, en esa medida, se considera que la identificación de las causas que generan la no credibilidad de los ciudadanos en las instituciones que administran justicia en Colombia, y las políticas públicas en esta materia deben ser prioridad para el Gobierno Nacional.

En desarrollo del amparo al crecimiento de las mipymes, el Estado colombiano, en el entendido que en el progreso de las relaciones mercantiles entre estas empresas, o bien entre estas y sus clientes o proveedores, ocurren las normales controversias de los grupos humanos, protegió su acceso a la administración de justicia, por esa razón expidió la Ley de Arbitraje 1563 de 2012.

Cabe añadir que además de las funciones relacionadas con los asuntos mercantiles que tienen las cámaras de comercio, se encuentran otras tareas dadas por la ley para promover e impulsar los MASC, aportando elementos para el restablecimiento del tejido social.

Es un avance social que las cámaras de comercio desde su RSE realicen esfuerzos para promover la solución pacífica de los conflictos como gestoras de paz en los territorios o en su círculo de influencia.

Basándose en su normatividad, la CCB, en el desarrollo de la RSE, además de incluir dentro de su reglamento el arbitraje social, en cumplimiento de lo establecido por la ley, creó el arbitraje mipymes y promovió jornadas gratuitas de esta innovadora figura con la finalidad de permitir el acceso a la justicia. Este nuevo estamento no solo fue creado para las micro, pequeñas y medianas empresas, sino que también permitió la participación de las personas naturales que hubiesen tenido relaciones comerciales con ellas. Lo anterior tuvo lugar entre los años 2009 y 2016 dando un paso adelante frente a la Superintendencia de Sociedades.

Las Jornadas Gratuitas de Arbitraje Mipymes fueron significativas para las empresas porque 
se beneficiaron al tener una posibilidad para atender sus diferencias, oportunidad que fue bien aprovechada por las mipymes, dado que pudieron dialogar acerca de las controversias existentes entre ellas mediante un procedimiento rápido y gratuito, ante un árbitro y sin necesidad de un apoderado judicial.

Por otra parte, es preciso señalar que, la CCB ha fortalecido sus procesos apoyándose en la investigación, publicación, formación y desarrollo de eventos académicos en pro del mejoramiento de los mecanismos para acceder a la justicia.
En atención a la situación social, política, económica y de salud -sobre todo por las graves secuelas y afectaciones que ha dejado la pandemia para las personas naturales y jurídicas- que llevó a la quiebra a muchas de ellas y repercutió en el crecimiento exponencial de la conflictividad, es pertinente pensar en el fortalecimiento de métodos alternativos para apoyar la justicia estatal. Estos deben ser promovidos por entidades de orden público y privado, en cuanto garantes del deber de solidaridad que es fundamento del Estado social de derecho en el que se basa la democracia colombiana.

\section{BIBLIOGRAFÍA}

- Ana Cecilia Serna Román vs. Asesores inmobiliarios Acseim Ltda., (15 de diciembre de 2011).

- Araújo, R. (2011). "Acceso a la justicia y tutela judicial efectiva. Propuesta para fortalecer la justicia administrativa. Visión de derecho comparado". Estudios SocioJurídicos, 13(1), pp. 274-291.

- Asamblea Nacional Constituyente. (1991). Constitución Política de Colombia. Bogotá: Legis.

- Bag's King Ltda. en acuerdo de reestructuración vs. Master Química Ltda., (25 de marzo de 2011).

- Benetti, J. (2018). "Los procedimientos arbitrales". Revista de la Academia Colombiana de Jurisprudencia, (368), pp. 145-163.

- Cámara de Comercio de Bogotá [CCB]. (2014). La Cámara de Comercio de Bogotá y Supersociedades se unen para impulsar la solución de controversias empresariales. Disponible en file:///C:/ U s e r s / H P / D o wn lo a d s / L a \% 20 C\%C3\%A1mara\%20de\%20Comercio\%20 d e \% 20 B o g o t \% C $3 \%$ A $1 \% 20$ y \% 20 Supersociedades.pdf

- Cámara de Comercio de Bogotá [CCB]. (2017a). Documento Estratégico
"Construcción de paz desde Confecámaras y las Cámaras de Comercio de Colombia". Bogotá: Fundación Ideas para la Paz.

- Cámara de Comercio de Bogotá [CCB]. (2017b). Informe final del diagnóstico del arbitraje en el territorio nacional. Bogotá: CCB.

- Campo, E. (2016). La conciliación en la institución y los efectos de la misma en el ordenamiento jurídico colombiano. (Tesis de grado). Universidad Santo Tomás. https://repository.usta.edu. co/bitstream/handle/11634/2072/ Mulatoedufamer2017.pdf?sequence $=1$

- Cardona, D., Montenegro, A., y Hernández, H. (2017). "Creación de empresa como pilar del desarrollo social e interal de la región Caribe: apuntes críticos". Saber, Ciencia y Libertad, 12(1), pp. 134-143.

- Cardozo, C. (2015). La jurisprudencia mercantil de la Corte Suprema de Justicia entre 1887 y 1916. Bogotá: Universidad del Rosario.

- Castilla, K. (2012). Acceso efectivo a la justicia. México: Editorial Porrúa.

- Centro de Arbitraje y Conciliación. (2014). Reglamento de Procedimiento de Arbitraje Mipymes y Arbitraje Social. Disponible en file:///C:/Users/HP/Downloads/Reglame 
nto + de + Procedimiento + de + Arbitraje+Mip ymes+y+Arbitraje+Social.pdf

- Centro de Arbitraje y Conciliación; Cámara de Comercio de Bogotá. (2017). Tertulia "Perspectivas del arbitraje social en Colombia". Disponible en https:// www.centroarbitrajeconciliacion.com/ Noticias/2017/Tertulia-Perspectivas-delarbitraje-social-en-Colombia

- Congreso de la República de Colombia. (1890). Ley 105 del 24 de diciembre de 1890. [Sobre reformas a los procedimientos judiciales]. Bogotá.

- Congreso de la República de Colombia. (1948). Decreto 2158 del 24 de junio de 1948. [Sobre Procedimientos en los juicios del Trabajo]. Bogotá.

- Congreso de la República de Colombia. (1970). Decreto 1400 del 6 de agosto de 1970. [Por el cual se expide el Código de Procedimiento Civil]. Bogotá.

- Congreso de la República de Colombia. (1971). Decreto 410 del 27 de marzo de 1971. [Por el cual se expide el Código de Comercio]. Bogotá.

- Congreso de la República de Colombia. (1989). Decreto 2303 del 7 de octubre de 1989. [Por el cual se crea y organiza la jurisdicción agraria]. Diario Oficial No. 39.013, del 7 de octubre de 1989. Bogotá.

- Congreso de la República de Colombia. (1996). Ley 270 del 7 de marzo de 1996. [Ley Estatutaria de la Administración de Justicia]. Diario Oficial No. 42.745, de 15 de marzo de 1996. Bogotá.

- Congreso de la República de Colombia. (2012). Ley 1563 del 12 de julio de 2012. [Por medio de la cual se expide el Estatuto de Arbitraje Nacional e Internacional y se dictan otras disposiciones]. Diario Oficial No. 48.489 de 12 de julio de 2012. Bogotá.

- Consejo Superior de la Judicatura. (2005). Descongestión de la Jurisdicción Civil. Bogotá: CSJ.

- Consejo Superior de la Judicatura. (2016).
Resultados del estudio de tiempo procesales. Bogotá: CSJ.

- Corte Constitucional de Colombia. (1996). Sentencia C-037 del 5 de febrero de 1996. Sala Plena de la Corte Constitucional. M.P: Vladimiro Naranjo Mesa. Bogotá.

- Corte Constitucional de Colombia. (2002). Sentencia C-426 del 29 de mayo de 2002. Sala Plena de la Corte Constitucional. M.P: Rodrigo Escobar Gil. Bogotá.

- Corte Constitucional de Colombia. (2011). Sentencia T-799 del 21 de octubre de 2011. Sala Plena de la Corte Constitucional. M.P: Humberto Antonio Sierra Porto. Bogotá.

- Corte Constitucional de Colombia. (2013). Sentencia C-279 del 15 de mayo de 2013. Sala Plena de la Corte Constitucional. M.P: Jorge Ignacio Pretelt Chaljub. Bogotá.

- Cortés, I. (2015). "El acceso a la justicia a la luz del Estado social de derecho en Colombia". Revista Científica "General José María Córdova", 13(16), pp. 81-103.

- Daniel Felipe Cardona Aranda vs. Collegiate sports of America S. A. S., (27 de marzo de 2012).

- Ferreira Ospino, J. (2010). "Caracterización del modelo de justicia de Rawls-Dworkin: elementos para una comprensión del estatuto epistemológico de la filosofía del derecho". Jurídicas CUC. 6(1), pp. 12-30.

- Gálvez, E. (2014). "Tecnologías de Información y Comunicación, e innovación en las mipymes de Colombia". Cuadernos de Administración, 30(51), pp. 71-79.

- Gálvez, E., y García, D. (2012). "Impacto de la innovación sobre el rendimeinto de la mipyme: un estudio empírico en Colombia". Estudios Gerenciales, 28(122), pp. 11-27.

- García, L., y Ramírez, R. (2016). "Égida de una administración de justicia precaria: derecho de acceso a la administración de justicia y pluralismo jurídico débil en Colombia". IUSTA, 2(33), pp. 29-39.

- Garzón, K. (2018). Causas determinantes de fracaso de emprendimientos en Colombia 
antes de los 5 años. Disponible en http:// hdl.handle.net/10654/17782

- González, J. (2018). "La acción procesal, entre el derecho a la tutela judicial efectiva y el acceso a la justicia". Nuevo Derecho, 14(23), pp. 21-43.

- Grasa, R., Carvajalino, G., y Duque, P. (2019). Construcción de paz y valor compartido. Retos y oportunidades del sector empresarial en Colombia. Bogotá: CCB.

- Herrán, O. (2013). "El alcance de los principios de la administración de justicia frente a la descongestión judicial en Colombia". Revista Prolegómenos. Derechos y Valores, 16(32), pp. 105-122.

- Illera, M. (2017). Las formas alterantivas de resolución de conflictos : un análisis desde el ámbito de las relaciones sociales $y$ de los ppios de la admon de justicia en Colombia. (Tesis doctoral) Universidad de Castilla - La Mancha. Obtenido de https://ruidera.uclm.es/xmlui/ bitstream/handle/10578/17860/ TES I S \% 20 I l l e r a $\% 20 \mathrm{~S}$ a n tos. pdf? sequence $=1 \&$ isAllowed $=\mathrm{y}$

- ISO 26000, 2010. Guía de Responsabilidad Social. Disponible en https://www.iso.org/ obp/ui\#iso:std:iso:26000:ed-1:v1:es.

- Jesús Jaime Ayala Estrada vs. Fivecon Group S. A. S., (5 de febrero de 2014).

- López, J. (2016). La credibilidad en el sistema de justicia en Colombia. Factores explicativos. Disponible en http:// manglar.uninorte.edu.co/bitstream/ handle / 10584 / 5824 / 72247311. pdf? sequence $=1 \&$ isAllowed $=y$

- Makroplásticos Ltda. vs. Arte y Diseño Modular J\&R Ltda., (14 de abril de 2010).

- María Lucero Quintero Arias vs. Jennifer Reina Rojas, (10 de septiembre de 2013).

- Mata, M. R. (2010). "Mercadeo social, responsabilidad social y balance social: conceptos a desarrollar por instituciones universitarias". Telos, 12(1), pp. 29-42.
- Melgarejo, Z., Vera, M., y Mora, E. (2014). "Competitividad de la Mipyme y desarrollo Regional. Estudio del caso colombiano". Tendencias, 14(2), pp. 184-215.

- Megavans S.A. (accionante) vs. Organización de viajes y turismo EU-Orvitur Ltda., (4 de febrero de 2011).

- Naizir, J. (2019). "Arbitrabilidad objetiva: ¿qué se puede y qué no se puede someter a arbitraje nacional según las fuentes colombianas de derecho?" Vniversitas, 68(139), pp. 1-1.

- Nonal-Haley, J. (2016). "Mediation and Access to Justice in Africa: Perspectives from Ghana". 21 Harvard Negotiation Law Review (59), pp. 1-49.

- Ortegón, S. (2019). "La arbitrabilidad subjetiva en rl contrato de fiducia en Colombia". Revista Estudios Socio-Jurídicos, 21(1), pp. 177-207.

- Osorio, M. (2012). "Arbitraje: un caso en contra de la constitucionalización de los mecanismos alternativos de solución de conflictos". Revista de Derecho Privado, (47), pp. 1-34.

- Peña, H. (2018). "Panorama de las necesidades jurídicas en los centros de conciliación y arbitraje". Pensamiento Jurídico, (48), pp. 185-232.

- Perea, A. (2013). El arbitraje para mipymes alternativa eficiente para solucionar conflictos. Disponible en https://www. enfoquederecho.com/2013/10/11/ arbritraje-para-mipymes-alternativaeficiente-para-solucionar-conflictos/

- Pérez,J. (2017). "El concepto y la natruraleza del arbitraje comercial en el ordenamiento jurídico colombiano". Justicia, (32), pp. 259-282.

- Pineda, N. (2017). El arbitraje comercial en Colombia - Pacto arbitral en el Estatuto de Arbitraje nacional e internacional frente a la jurisdicción ordinaria a partir del Código General del Proceso. Disponible 
en https://repository.unimilitar.edu. co/bitstream/handle/10654/16386/ PinedaLemus NelsonEnrique 2017. pdf?sequence $=1 \&$ isAllowed $=y$

- Ravina-Ripoll, R., Gálvez-Albarracín, E., y Otálvaro-Marín, B. (2020). "Post acuerdo de paz: Una etapa a legitimar bajo el calediscopio de las mipymes colombianas". Jurídicas CUC, 16(1), pp. 303-322.

- Restrepo, D. (2014). "La arbitrabilidad objetiva en el derecho de arbitraje". EAFIT, 5(1), pp. 63-80.

- Restrepo, J., Loaiza, O., y Vanegas, J. (2019). "Determinants of innovation. A multivariate analysis in Colombian micro, small and medium-sized enterprises". Journal of Economics, Finance and Administrative Science, 24(47), pp. 97-112.

- Rey, P. (2013). "El arbitraje y los ordenamientos jurídicos en Latinoamércica: un estudio sobre formalización y judicilialización". Vniversitas, (2016), pp. 199-237.

- Rodríguez, M. (2012). "Una aproximación al régimen del arbitraje nacional del nuevo Estatuto del Arbitraje en Colombia Ley 1563 de 2012". Revista de Derecho Privado, 23, pp. 367-405.

- Rosado, F., y Velásquez, L. (2017). "Garantía de los mecanismos legales en la aplicación del principio de tutela judicial efectiva en el Código General del proceso en Colombia". Derectum. 2(2), pp. 77-102.

- Rota, M., Lalinde, S., Santa, S., y Uprimny, R. (2014). Ante la justicia, necesidades jurídicas y acceso a la justicia en Colombia. Bogotá: Centro de Estudios de Derecho, Justicia y Sociedad, Dejusticia.

- Rubén Darío Pineda Torres vs. Asociación de joyería y actividades afines de Bogotá y Cundinamarca Asjoyería Bogotá, (11 de diciembre de 2009).

- Rueda, E. (2015). Constitucionalización del proceso arbitral en Colombia. Santander: Universidad Industrial de Santander.

- Ruíz, J. (2013). Diseño de modelo de Responsabilidad Social Empresarial en pyme constructora araucana. Disponible en https://core.ac.uk/download/ pdf/17037226.pdf

- Salcedo, Á. (2011). "En torno a la naturaleza jurídica del arbitraje". Revista Análisis Internacional, (2), pp. 147-154.

- Silva, F., y Martínez, G. (2019). "La justicia alternativa como derecho humano". Jurídicas CUC, 15(1), pp. 263-284.

- Sociedad Campo Elías Gamboa S. A. S. vs. Alfagres S. A., (5 de agosto de 2011).

- Tavera, D. (2012). Estudio de las causas y manejo de conflictos en mipymes familiares en Bogotá D.C. (Tesis de maestría). Disponible en https://repositorio.uniandes.edu.co/ bitstream/handle/1992/11640/u608795. pdf?sequence $=1$

- Torres, M., y Iregui, P. (2020). Las acciones constitucionales: reflexiones sobre sus avances y retos. Bogotá: Universidad del Rosario.

- Toscano, F. (2015). "Algunas facetas del derecho fundamental al acceso efectivo a la administración de justicia en Colombia". Revista de Derecho Privado, 29, pp. 213-232.

- Villalba, J., y Moscoso, R. (2008). "Orígenes y panorama actual del arbitraje". Prolegómenos. Derechos y Valores, 11(22), pp. 141-170.

- Watchtower Security Ltda. vs. Conjunto residencial Dardanelos II P.H, (25 de enero de 2012).

- Zappalà, F. (2010). "Universalismo histórico del arbitraje". Vniversitas, 59(121), pp. 193-216. 